\title{
Printing On Paper: Costly Nuisance Or Pedagogical Imperative?
}

Pranjal Gupta, University of Tampa, USA

Erika Matulich, University of Tampa, USA

Baris Yalabik, University of Bath, UK

\begin{abstract}
What are the typical printing behaviors of students? What is the extent of wastage? What are student attitudes towards different pay-per-print schemes? What might be strategies for educational institutions to achieve less printing while not impeding pedagogical quality?

"If all printers were determined not to print anything till they were sure it would offend nobody, there would be very little printed" - Benjamin Franklin
\end{abstract}

Keywords: Pay for Print; College Printing Policies; Print Management Education

\section{INTRODUCTION}

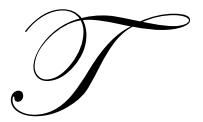

he world's first computer printer was a 19th century mechanically-driven apparatus invented by Charles Babbage for his Difference Engine. It is doubtful that Babbage foresaw this invention as the start of a product whose variations would sell more than 20 million units a year by the first years of the $21^{\text {st }}$ century, but printers have since become a routine part of doing business and have become commonplace in offices, homes, and schools (Lewis 2007).

There are several reasons for the flourishing market for printers and subsequent printing. First, with information search costs being extremely low on the Internet (Su 2008) and the quantity of information being virtually limitless, users search for and consume vast quantities of information from this source. Second, information and file sharing through servers within networks, through web-based servers, and through file sharing via e-mail and other mechanisms has become very easy. Third, storage capacities and portability of digital information storage devices have increased dramatically, making information copying, storage, retrieval, and use extremely simple.

One would expect the digital age to move most of information consumption from paper to computer screens, as the use of paper and ink has significant effects on the financial health of organizations or individuals and the environmental health of the planet. However, this paperless vision has not taken place. People still prefer to read off printed paper rather than computer screens (Geske and Bellur 2008). Given that people can now print much more thanks to the digital availability of tremendous amounts of information, such excessive printing can lead to significantly higher costs, both financially and environmentally.

A university or educational institution is one type of organization that is influenced by the trends mentioned above. Computer laboratories available for student use allow students to print not only class-related materials but also any other information that is available to them through the Internet. If printing behavior is not restrained somehow, the costs to the university can be overwhelming. On the other hand, it is important to recognize that some printing by students (papers, slides, etc.) is a necessary component of education, given that reading off printed paper seems much more agreeable than reading off computer screens. Thus, providing students with sufficient ability to be able to print educational materials is of pedagogical interest to universities and educational institutions. Potential strategies to balance the need to limit financial and environmental costs to educational institutions and at the same time ensure that students can print sufficiently to study effectively is the focus of this research. 


\section{THE CURRENT CASE}

Our context is The University of Tampa (UT), a private university of about 5,500 students, where printing is currently free to students with no page limits on printing. The current problems under such a system are that students are involved in not only printing course-related required materials, but also non-course related printing (e.g. flyers for a personal business) and the printing of extensive resources such as e-books. This context is particularly salient as it allows investigation of behaviors and attitudes of students currently in a free and limitless printing environment. This environment allows assessments of printing excesses, if any, and attitudes and thoughts towards any form of printing curbs.

We utilize a structured research approach and various methodologies to examine student printing behavior and priorities, and investigate student attitudes toward different pay-per-print schemes. We first present secondary research by benchmarking the experiences of other universities and educational institutions that have implemented printing policies. Next, we report the results of a series of small focus groups intended to understand student thoughts and attitudes regarding policies that would limit financial and environmental costs but not pedagogical quality. Last, we report the results of a large scale student survey that measure their attitudes towards printing, attitudes and thoughts towards various solutions and their printing needs and behaviors. We conclude with a series of recommendations that may help to achieve the parallel goals of cost reduction and pedagogical effectiveness.

\section{THE BENCHMARKS}

Printing policies used by universities are diverse, with policies ranging between straight pay-per-page, fixed printing fees per semester, awareness programs, and printing quotas with per-page charge thereafter. We briefly describe some examples that illustrate some of these options.

There are many universities utilizing straight pay-per-print policies. For example, with the objective of reducing printing costs, the School of Medicine at Pennsylvania State University implemented a straight pay-perprint system in 2004 and found that printing went down by 56\% while the number of documents printed doublesided went up 98\%. To ensure student acceptance, their policy included a liberal refund policy, training and e-mail notifications. Overall, they found that their program was successful and achieved lower costs while maintaining good acceptance for the system among students (Pay To Print FAQ).

The objectives at The College of New Jersey were focused more on environmental education and limiting waste than recovery of printing costs. They implemented an environmental awareness campaign and imposed a 600-page quota with the option to purchase additional pages and found that $93 \%$ of students stayed within the quota, which amounted to a $41 \%$ reduction in printing-related costs (Print Sense FAQs).

The University of Miami has implemented a pilot program that aims to curb printing by monitoring printing habits, double-sided printing and creating awareness amongst students of their printing habits and the associated impact. It is important to note that printing will remain free during the pilot study. The theoretical argument behind such an approach is that awareness of environment and cost impact, coupled with print monitoring systems, should curb printing behavior automatically (Document Services).

Last, in a survey of 107 schools, a University of Richmond study found that more than $90 \%$ of the schools had already implemented pay-per-print policies, with $61 \%$ of those schools providing free printing quotas before charging students for printing pages exceeding the quota. Interestingly, the survey reported a wide range in the initial free quota amount (Printing Survey 2007).

Overall, the secondary research phase provides three important insights. First, the ubiquity of printing facilities and the preference for printed study materials compared to digital information has led to a considerable increase in the quantity of printing. Further, a by-product of uncontrolled printing is that up to $35 \%$ of such printing may be avoidable. Second, there seems to be a direct correlation between some checks and curbs on printing on the amount of printing done by students. Third, there seem to various printing facilities options to consider depending on the objectives of the institution. For instance, objectives could range from using print facilities as a profit center 
for the institution, to creating student awareness of the impact of excessive printing in terms costs and environmental damage, to printing cost containment to waste management and environmental protection. The decision to choose a particular printing policy should stem from the objectives that the institution has (Nerdozza and Stern 2006).

\section{FOCUS GROUP RESEARCH}

Next, having gained insights from the institutional perspective, we report on the next of phase of research. This phase was focused on the student perspective. We report results of a series of 3 focus groups of both graduate and undergraduate students at the University of Tampa. The purpose was to understand the student needs for printing and their attitudes toward policies that could potentially curb printing or impose charges to do so.

Three focus groups of 3-5 graduate and undergraduate students were formed in order to get a preliminary understanding of the student perspective. There were two main purposes of the focus groups. First, small group discussions often provide deeper qualitative insights into issues that may be harder to investigate in survey research. Second, such qualitative research helps to structure and guide larger-scale survey investigations. In the following paragraphs, we briefly discuss the main themes that were probed and the responses generated in the focus group discussions.

Respondents were asked their thoughts about unrestricted printing on campus. Not surprisingly, students were generally in support of unrestricted printing. However, further probing revealed a deeper and more intuitively acceptable set of reasons for this stance. They explained that professors were beginning to require more class materials printed from online sources. Further, e-books, online articles, and other online materials were just more comfortable and faster to read printed than on computer screens. Thus, the underlying rationale for their unrestricted printing seemed to stem from their desire to ensure that freedom to print would ensure their learning and education were not hindered. However, many did acknowledge that there was some waste associated with printing and that recycling programs and campaigns to create awareness would curb wasteful printing behaviors. They also cautioned that some printing by former or non-students did occur and could contribute to printing excesses that have been observed.

Students were asked about the breakdown of printing they or others did that was course-related, job-related, or personal. Nearly every student reported that the majority or entirety of their on-campus printing was course related, but everyone had observed abuse of this use by others. This response could have been partially driven by the fact that respondents may have been reluctant to reveal their printing behaviors or that the majority of non-school related printing is being done by a small minority.

Next, students were asked to suggest programs that could increase accountability and limit overuse of on-campus printing. Results here were very insightful. Students suggested that campaigns to educate and inform students about the environmental impact of printing excesses would have a significant impact on printing behavior. Thus, students here were peripherally accepting that printing excesses did indeed exist. Further, they also alluded to the fact that students would respond favorably if an appeal was made to curb printing to limit environmental damage. Thus, campaigns to create awareness of environmental issues may likely lead to meaningful reductions in printing. Interestingly, students were willing to accept printing quotas to work within (suggestions ranged from 500-2,000 pages a semester). However, they cautioned that override abilities were necessary to ensure they could continue to print beyond the quota if their coursework required so. Further, another suggestion to impose controls would be to ask professors and instructors to provide more of the required materials in class or in the bookstore. Importantly, this line of questioning revealed two important insights. First, students in higher education are likely to have stronger awareness and concern for environmental issues and that these beliefs and values could be invoked to create some curbs on wasteful printing.

Next, a sense of the experience that students had with pay for print programs was asked. Surprisingly, the majority of the respondents reported having first-hand experience with a payment system related to university on-campus printing. These ranged from straight pay-per-print policies to print quotas. The consensus was that overall effect would be that on-campus printing would decrease and that some would print more at home. Respondents also cautioned that printing was an important enough issue that it could potentially impact student perceptions about the university administration. 
Finally, students were asked about administrative arrangements details of programs that they thought would be most effective. A large majority of respondents reiterated that a system with a quota on the number of pages allocated per semester or month could be made workable. Some suggested a roll-over plan to allow students to manage their printing over a period of time better. This system could serve as a reward for "paper thriftiness" and also allow students to manage their own printing needs during heavy and light printing periods while avoiding any bureaucracy. Other useful suggestions that came forth were to install more efficient printers to curb costs, default to double-sided printing and use of institution specific currency (e.g., Spartan Dollars at the University of Tampa) on stored value cards to facilitate printing.

Overall, the focus groups revealed some interesting insights. Of these, the implicit acknowledgement that considerable wastage in printing occurs was paramount. Following this, it was also encouraging to note that student bodies in today's educational institutions are likely to be more concerned about waste and environmental protection. Thus, stemming from these concerns, they are more likely to see the value of programs and incentives to protect the environment through waste limitation. From the administrative perspective, policies that limit printing through reasonable quotas may be workable and acceptable by students. Further, to streamline printing management, various suggestions such as default double-sided printing, more instructor-provided materials and rollover print quotas were suggested. Next, a large scale survey of the student body was done to validate the preliminary findings from the focus groups.

\section{STUDENT SURVEY ON PRINTING SOLUTIONS}

To gather a larger scale response from the student body, an online survey was conducted. To ensure adequate representation, an internal system of "global" e-mail including every University of Tampa student was used, thus resulting in a probability census. The online survey instrument was developed using a web-based survey administration company (SurveyMonkey). The survey instrument was developed based on the secondary benchmark research, results and suggestions made in the focus groups, and in consultation with the administrative departments at the University. The instrument was pre-tested by graduate students and revised several times to ensure comprehension and validity.

Students were first invited to participate by sending them an official e-mail, rationale behind the study, and a link to the survey instrument. To increase response rates, a reminder was sent within 48 hours of the initial e-mail. The frame was the entire student population (over 5,000 students) and 811 usable responses resulted in a response rate of close to $14 \%$. In the following paragraphs we briefly highlight the salient survey results.

Importantly, the findings largely support what was found from the focus group discussions. In a more anonymous and impersonal setting, students did report that up to $25 \%$ of their printing was unrelated to their coursework or class-related research work (Table 1). This result is potentially significant amount of printing is a source of waste perhaps attributable to no printing curbs. It is interesting to draw a parallel with the secondary research where, even conservatively, about $33 \%$ of all printing is waste. Thus, in institutions where printing is unrestricted, it is seems reasonable to expect that if curbs were made such that most printing were restricted to academic-related printing, costs could come down by at least 25\%. Also, from Table 1, it is apparent that a significant amount of printing is done by students to fulfill their responsibilities in on-campus or other jobs they have or in the student activities they are involved in. Telling figures are that a staggering $9 \%$ of respondents report that between $25-50 \%$ of their printing was personal. From Table 1 again, it is apparent that even in a self report, small numbers of students are reporting large quantities of non-coursework or studies related printing. Thus, it seems likely that a minority of students may be the cause for a majority of the improper printing occurring. This would suggest that systems that track printing behavior and provide students with the mechanisms to track their own printing may cut down on wasteful printing. 
Table 1: Reported Printing Activity by Type

\begin{tabular}{|l|c|c|c|c|}
\hline \multirow{2}{*}{ Extent of Printing } & \multicolumn{4}{|c|}{ Type of Printing Activity* } \\
\cline { 2 - 5 } & Job/work-related & Activity-related & Personal-related & School-related ** \\
\hline $0-25 \%$ & $75.5 \% *$ & $61.3 \%$ & $71.3 \%$ & $2.1 \%$ \\
\hline $25-49 \%$ & $4.3 \%$ & $10.4 \%$ & $9.2 \%$ & $1.6 \%$ \\
\hline $50-74 \%$ & $2.2 \%$ & $6.9 \%$ & $2.0 \%$ & $10.5 \%$ \\
\hline $75-100 \%$ & $1.5 \%$ & $4.9 \%$ & $1.0 \%$ & $69.3 \%$ \\
\hline
\end{tabular}

* Of the four categories, only "School-related" pertains to academic coursework/research related printing

** Note that percentages reported are based on the total sample. The columns do not all add to 100\% of respondents because missing responses are omitted here for brevity.

Next, the results of the survey suggested that students were generally ignorant of some very important mechanisms to cut down on paper wastage. For instance, half of the respondents did not know how to print double sided, or even check on their own printing activity. Some also reported that printing multiple slides per page of a PowerPoint presentation was something they did not know. These results suggest perhaps the value of setting default printing parameters, with the option to change them, to ensure less paper and supplies costs. For example, default double sided printing and 3-slides per handout for lecture materials may be considered by institutions.

There were significant differences in attitudes between graduate and undergraduate students and business versus nonbusiness students, as measured by independent samples t-tests $(\mathrm{p}<.05)$. In general, both graduate students and business students had higher printing needs, and sought higher quotas and more liberal policies than did undergraduate and nonbusiness students. Younger students (e.g. freshmen and sophomores and those under age 25) had stronger environmental attitudes than did older students.

Finally, the attitudes of the respondents seemed to mirror what was found in the focus group studies. Largely, students tended to reject pure pay-per-print policies. The consensus seemed to be that pure pay-per-print policies may curb some excesses but would not lead to more online reading and may reduce the quality of education. Thus, from the pedagogical perspective, it is imperative that institutions allow for sufficient printing for students to learn unimpeded. The challenge is to provide that and limit all other printing. Surprisingly, only 55\% of the respondents sought limitless printing; they generally were agreeable to reasonable quotas. In terms of hybrid policies, the results show that students believe quotas can work well in tandem with more instructor-provided materials and reasonable costs for printing beyond the quotas.

In summary, the survey revealed that uninhibited printing leads to excesses that can be reduced. These could be reduced through student education and training coupled with default settings that could lead to printing thrift (e.g., default double sided printing, default 3-slides-a-page Powerpoint handouts etc.). More importantly, from the pedagogical perspective, the survey results reiterate that educational materials in print form remain very important learning tools despite the same materials being available in online digital form. Thus, for effective education, it is imperative that educational institutions recognize that sufficient printing facilities are paramount.

In the concluding section we bring together all the results and provide specific recommendations for institutions considering printing policies.

\section{CONCLUSIONS}

Paying for printing is one easy way for institutions to cut administrative costs and pass those costs to the students (Olsen 2002). However, from the perspective of educational quality, pure pay-per-print programs are very likely to have a negative impact. Our results suggest that the ability to print educational materials is an important part of educational quality. To the extent that digitized educational materials do not seem to be a good substitute for the same material in printed form, providing sufficient printing resources to students seems critically important. However, the research also shows that unimpeded printing leads to excesses and waste that can inflate printing as much as $35 \%$. The challenge for educational institutions is to provide a sufficient printing quota for students to facilitate their learning but impose sufficient per-page costs beyond the quotas to discourage waste. The quota amounts will vary, of course, between and within institutions. From the administrative perspective, it is important to 
recognize that student printing needs may vary by discipline and adjustments will need to be made accordingly.

From the baseline quota-based printing, our results also suggest that liberal policies of rolling over unused print quotas, policies to override quotas if schoolwork necessitates it and reasonable per-page costs post-quota would be useful complements. The objective should be to ensure students are not inhibited in printing for education but are for all other forms of printing.

The results also suggest that monitoring systems that inform students and administrators of printing quantities may help to limit waste and unnecessary printing. Also, training and default settings that save paper (e.g., default double sided printing) are likely to have significant impact as well. Last, periodic campaigns of environmental consciousness and reminders of the detrimental impacts of frivolous printing are likely to lead to reductions in such printing in today's higher education students.

\section{AUTHOR INFORMATION}

Pranjal Gupta is an Associate Professor of Marketing at the University of Tampa and teaches E-Commerce courses. He is involved with several campus technology initiatives and performs research in technology pedagogy and electronic commerce. E-mail: pgupta@ut.edu

Erika Matulich is a Professor of Marketing at the University of Tampa, former director of the Masters of Science in Marketing Program, and chair of the University Instructional Technology Committee. Her research interests include technology applications in the classroom. E-mail: ematulich@ut.edu

Baris Yalabik is a Lecturer in Operations and Supply Management at the Bath University School of Management. His research interests include corporate environmentalism and sustainability in operations management. E-mail: b.yalabik@bath.ac.uk

\section{REFERENCES}

1. Document Services and Solutions, University of Miami. 2007. http://www6.miami.edu/UMH/CDA/UMH_Main/0,1770,56778-1,00.html

2. Geske, Joel and Saras Bellur. "Differences in brain information processing between print and computer screens: Bottom-up and top-down attention factors." International Journal of Advertising. Eastbourne: 2008. Vol. 27, Iss. 3; p. 399.

3. Lewis, Michael A. "Charles Babbage: Reclaiming an Operations Management Pioneer." Journal of Operations Management. Columbia: Mar 2007. Vol. 25, Iss. 2; p. 248.

4. Nerdozza, Frank, and Nadine Stern. "PrintSense: Making sense of Print Management." Educause Center for Applied Research: Research Bulletin. Issue 6 (14 Mar 2006).

5. Olsen, F. "Ten Ways Colleges Can Cut IT Costs." The Chronicle of Higher Education, 4 Oct 2002 49(6), p. A39.

6. "Pay To Print: Frequently Asked Questions." The George T Harrell Library at Penn State. 14 October 2008. http://www.hmc.psu.edu/library/services/print.htm

7. "Printing Survey." 12 Sept 2007. University of Richmond School of Law. http://law.richmond.edu/librarytech/printsurvey.php

8. "Print Sense FAQs - College of New Jersey." http://www.tcnj.edu/ printing/faq.html, 2006.

9. Su, Bo-chiuan. "Characteristics of Consumer Search On-Line: How Much Do We Search?" International Journal of Electronic Commerce. Armonk: Fall 2008. Vol. 13, Iss. 1; p. 109. 